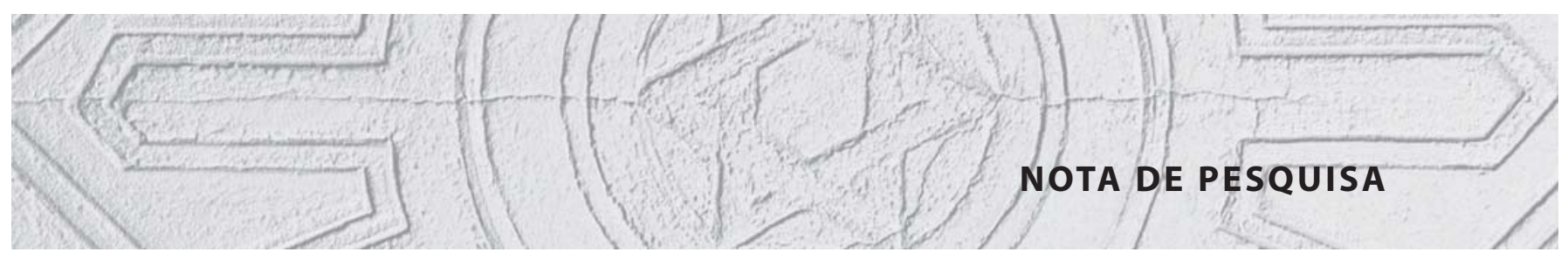

\title{
O traço francês na arquitetura do Recife: o Hospital Pedro II*
}

\author{
French lines in Recife architecture: \\ Pedro II Hospital
}

\section{Geraldo Pereira}

Médico; membro do Conselho Estadual de Cultura de Pernambuco, professor emérito/Universidade Federal de Pernambuco.

Rua Neto de Mendonça, 230/202 52050-100 - Recife - PE - Brasil pereira@elogica.com.br 
A história da assistência médica em Pernambuco começa em meados do século XVI, conforme Pereira da Costa, que dá notícia da existência da Santa Casa de Misericórdia de Olinda já em 1540. O autor faz alusão ainda ao fato de que essa referência consta na página 17 do Livro do Tombo da Freguesia de Nossa Senhora da Luz (Pereira da Costa, 1951). Mas há quem duvide dessa precedência olindense, dando à Santa Casa de Santos a primazia, como faz Ivamoto (1998). O padre Serafim Leite, historiador da Companhia de Jesus, no entanto, faz menção à circunstância de que, em 1549, a cidade de Santos ainda não dispunha de hospital. Menciona, aliás, que o padre Leonardo Nunes, tendo chegado ao povoado de 'Todos os Santos' em 1550, soube que ali não havia um hospital (Leite, 1950). O Guia das Santas Casas de Misericórdia no Brasil, coordenado por Yara Khoury (2002), cita igualmente o hospital e divulga fotografia do local, com o prédio original ainda em pé.

Há registros, também, de dois hospitais no Recife no século XVII, durante a ocupação holandesa, instalados por iniciativa do conde Maurício de Nassau. Heloisa Gesteira (2004, p.13) menciona a existência de pelo menos um hospital na área urbana do Recife: "Marcgrave realizou mais viagens pelo interior do continente do que Piso, que era médico e concentrou suas atividades no Recife, trabalhando num hospital dentro do núcleo urbano". Um documento holandês do século XVII, dá conta do esforço em se instalar mais um estabelecimento: "Cartas dos anos de quarenta [1640] nos informam que o grande número de doenças, entre as quais a disenteria desempenhou o papel principal, produzidas pelo clima, água de má qualidade, resfriamento e extravagâncias de modo de vida, fez necessária a fundação de um segundo hospital" (citado em Watjen, 1838, p.393). É de Rostand Paraíso (2004), em livro que trata da antiga Faculdade de Medicina do Recife - A Velha Senhora -, a alusão ao fato de que a nova instituição pernambucana teria chegado para substituir o Grande Hospital, resultante da fusão do Hospital dos Pobres da Ribeira (1802), mais tarde denominado Hospital São Pedro de Alcântara (1828), com o Hospital do Paraíso e São João de Deus. Em seguida, o Grande Hospital foi transferido para o Convento do Carmo (1833), ocupando as dependências do antigo Hospital Militar. E daí - com o objetivo de possibilitar a devolução das instalações aos carmelitas - transferido para a localidade dos Coelhos, em 14 de março de 1846, onde permaneceu até a inauguração da nova sede, no mesmo bairro, em março de 1861.

O Hospital Pedro II surge então em um cenário urbano diferente, na Recife oitocentista (1861), onde havia sido fundada, em 1841, a Sociedade de Medicina de Pernambuco, instituição que deu ares científicos ao exercício do mister hipocrático. Tal Sociedade serviu, a princípio, como uma academia, reunindo os médicos, sobretudo os do Recife, em torno de discussões das doenças que grassavam de forma epidêmica, mas também visando ao debate dos casos clínicos considerados mais difíceis (Pereira, no prelo).

É neste cenário, de maior atenção às pessoas e um cuidado mais humanizado com a população carente - um ambiente no qual a destinação hospitalar já tinha o objetivo da cura e não mais a expectativa da morte - que nasce o Hospital Pedro II, cuja pedra fundamental foi assentada em 25 de março de 1847. A instituição foi inaugurada em 10 de março de 1861, um domingo, 14 anos após a pomposa solenidade inicial. 
Trata-se da primeira construção no Recife destinada especificamente à área de saúde. A construção foi feita no estilo pavilhonar, adotado durante muito tempo em vários hospitais da Europa e das Américas. Esse estilo serviu de modelo às novas instituições construídas a seguir no estado e no país. O projeto da edificação nasceu das mãos de um engenheiro pernambucano, José Mamede Alves Ferreira (1820-1865), autor de outros importantes prédios no Recife, tais como o Ginásio Pernambucano, a Casa de Detenção e o Cemitério de Santo Amaro. Mamede estudou em Lisboa e em Paris e foi na Europa que tomou contato com as mudanças nas concepções prediais, especialmente no que diz respeito à arquitetura hospitalar (Rocha, 1960; Cabral, 2006; Inventário..., 2007).

O edifício está situado na localidade conhecida como Coelhos, como já mencionado, tendo sido elevado a $1,25 \mathrm{~m}$ do nível do terreno. Conta com fachada de $115 \mathrm{~m}$ e altura de quase $20 \mathrm{~m}$, o que confere imponência ao imóvel. Dispõe de um pátio central que mede $39 \mathrm{~m}$ de largura e 45,5m de fundo. Para esse ambiente convergem os pavilhões e as respectivas passagens de circulação da edificação. A referida área está contida por uma galeria de 2,85m de vão, ventilada e iluminada por arcadas romanas no pavimento térreo, e por janelas envidraçadas nos andares superiores. Se a construção fosse concluída como previsto no projeto, apresentaria 56 arcadas ao todo, com dez blocos de enfermarias, convergindo para o pátio central, separados por jardins internos. Seriam cinco blocos em cada lado do terreno: os da direita reservados às mulheres e os da esquerda aos homens (Rocha, 1960).

Quando da inauguração, no entanto, somente três desses blocos haviam sido finalizados, dois deles à esquerda e um à direita, e mais duas enfermarias no pavimento térreo. Em 1906, realizou-se uma expansão que concluiu o segundo bloco da direita e acrescentou mais uma enfermaria, no mesmo lado, também no térreo. Trata-se de uma construção com três pavimentos, em cujos pavilhões estão dispostas as enfermarias, todas dedicadas a algum santo ou santa da Igreja, como a Enfermaria Nossa Senhora do Bom Conselho. Na fachada principal do hospital, localiza-se o grande pórtico de entrada, ornado com duas colunas que sustentam um entablamento, em cujo centro foi colocada a figura da caridade, em fina cantaria lisboeta (Rocha, 1960; Inventário..., 2007).

Houve diversas iniciativas para angariar fundos com objetivo de terminar a construção entre março de 1847 e julho de 1860, como subscrições populares, à semelhança da que teve como objetivo instalar naquele mesmo local um abrigo da mendicância, logo em seguida transferido para outra instituição, em 1859. Foram igualmente criadas vinte loterias de cem contos de réis anuais, cujo rendimento era destinado, especificamente, às obras. No decorrer dessas iniciativas para angariar fundos, ocorreu um evento sui generis: um baile oferecido ao imperador Pedro II nas dependências do hospital, antes mesmo de sua inauguração. Em 22 de dezembro de 1859, a Associação Comercial de Pernambuco recebeu a sociedade local para uma festa em homenagem ao mandatário imperial que visitava a Província, à qual compareceram cerca de duas mil pessoas, lotando o recinto. O imperador Pedro II registrou, então, em seu diário: "O baile, por ocasião da minha visita à Província, fez com que a obra se adiantasse bastante... Ao menos o baile foi aqui útil, ainda que indiretamente" (citado em Rocha, 1960, p.71). Desse evento, ao que parece, restaram alguns desenhos ornamentais no andar superior, onde se imagina que tenha ocorrido o baile. 
A instituição inaugurada em 1861 tinha capacidade para cerca de 250 doentes, podendo chegar a trezentos em tempos de epidemia. Na abertura do hospital, 115 pacientes foram recebidos, todos provenientes do Grande Hospital que, na ocasião, ainda era tratado por alguns como Hospital do Paraíso. Dois dias após essa instalação solene, o doutor Praxedes Pitanga faria a primeira cirurgia, intervindo em um paciente italiano para sanar-lhe uma hérnia estrangulada, depois de ter ouvido em conferência os médicos Sá Pereira e Carlos Frederico, que concordaram com a indicação e assistiram ao procedimento. O paciente foi anestesiado com clorofórmio.

Naquele hospital, nos primeiros anos, pontificaram outros ilustres profissionais da medicina, entre os quais: Morais Sarmento (1844-1897), Lobo Moscoso (?-1897), José Soriano de Souza (1833-1895), Malaquias Gonçalves (1845-1907) etc. Nesta lista figura igualmente o doutor José Francisco Guimarães, experiente cirurgião, o primeiro a utilizar a anestesia geral em Pernambuco, a principio com éter e em seguida com clorofórmio (Rocha, 1960).

Alguns detalhes interessantes no "Regulamento para o Serviço Sanitário do Hospital Pedro II e dos estabelecimentos a cargo da Santa Casa de Misericórdia do Recife" (1898) merecem comentários à parte. Um deles diz respeito à recomendação da utilização dos serviços de enfermagem prestados pelas irmãs de caridade, como ocorria em vários países de tradição católica no mundo e, durante muito tempo, também no Recife. Chama atenção, ainda, o conteúdo de outro artigo, que figura como uma espécie de compromisso do diretor médico: o imperativo de se realizar, a cada mês de janeiro, uma estatística geral dos doentes tratados durante o ano anterior, com vistas à apresentação de tais informações ao provedor.

Uma tabela que consta dos "Relatórios sobre a Santa Casa de Misericórdia do Recife" (1880, p.14) dá conta do movimento no período. Entre 1860 e 1880, foram internados 45.521 doentes, dos quais 34.010 obtiveram alta, ao passo que 10.903 faleceram. Significa dizer, em termos aproximados - uma vez que os totais nem sempre correspondem à soma das parcelas - que a resolutividade foi superior a $75 \%$, e a mortalidade chegou a $24 \%$; números que, para a época, talvez tivessem uma significação valiosa.

A planta do Pedro II tem grande semelhança com a do Hospital Lariboisière, em Paris, cuja edificação data de 1854 , e é considerado o primeiro empreendimento nosocomial levantado de acordo com as normas de Jacques-René Tenon (1724-1816). O prédio seguiu, rigorosamente, as regras estabelecidas por esse médico, que modificou a ciência arquitetônica hospitalar apresentando novas propostas e princípios, que daí por diante nortearam muitos projetos de edifícios hospitalares no mundo. Tais normas recomendam que os prédios sejam divididos em blocos de até três pavimentos, os quais devem convergir para um pátio central retangular - um grande e belo jardim, no caso considerado. A separação dos pavilhões por um pátio interno facilita a iluminação e permite a ventilação, concorrendo ainda para a convivência de funcionários e pacientes. No Hospital Pedro II tudo foi feito como recomendado. Passou-se, então, a enxergar a instituição sob uma perspectiva diferente, aquela da cura, das intervenções terapêuticas e cirúrgicas. Afastava-se dessa maneira a ideia antiga, quase medieval, de que o ambiente hospitalar era um lugar no qual os doentes deveriam esperar o óbito: um morredouro. Foi de Tenon, ainda, a iniciativa de recomendar que os hospitais adotassem gestores médicos, tendo em vista a finalidade da instituição: a 
cura dos doentes. A similitude entre os dois projetos arquitetônicos, o do Lariboisière e o do Hospital Pedro II, vai desde o desenho da planta baixa aos arcos romanos e à disposição das enfermarias (Czaijkowski, 1993; Silva, 2001).

Até 1982, a Universidade Federal de Pernambuco foi a instituição mantenedora do hospital, em função de convênio com a Santa Casa de Misericórdia do Recife. Desde 1920, por iniciativa do médico Octávio de Freitas (1871-1949), fundador da Faculdade de Medicina do Recife, o Pedro II passou a servir como campo de prática aos alunos do curso médico (Freitas, 1944). Nessas seis décadas o Hospital foi tido como referência em Pernambuco e no Nordeste. Era comum que pacientes ambulatoriais e de consultório dos profissionais locais fossem levados à discussão clínica nos diversos serviços de que dispunha a instituição, reconhecida como o celeiro de formação dos mais destacados professores, clínicos gerais e cirurgiões do Recife e de várias das capitais da região. Concluído o Hospital das Clínicas no campus universitário, para lá foram transferidos os doentes e os equipamentos disponíveis em condição de uso, sob protesto de vários professores (Nogueira, 1982).

Depois dessa transferência, o Hospital Pedro II passou quase 28 anos desativado. Serviu à Secretaria Estadual de Saúde, acolhendo uma diretoria regional, e ao Núcleo de Estudos de Saúde Coletiva da Fiocruz. O que inquietou a sociedade pernambucana, e os médicos em particular, foi o interesse empresarial em transformar o prédio neoclássico em shopping center, interesse, aliás, vez ou outra registrado no Recife. É do presidente do Instituto de Medicina Integral Professor Fernando Figueira (Imip), o médico Antônio Carlos Figueira (1960- ), em entrevista à revista Movimento Médico a declaração de que um empresário português já vinha negociando o imóvel, quando ele próprio fez contato com a Arquidiocese de Olinda e Recife, manifestando a pretensão de ocupar o prédio (Um hospital..., 2010). O médico Rostand Paraíso (1930- ), por ocasião do esforço em se barrar semelhante empenho da iniciativa privada junto ao Hospital Ulysses Pernambucano, escreveu que "participara da luta para evitar que o Hospital Pedro II fosse negociado com particulares para um empreendimento imobiliário, campanha coroada de sucesso com a decisão do Imip - à frente, de uma maneira decisiva, Antônio Carlos Figueira - em restaurá-lo nas suas linhas originais" (Paraíso, 25 fev. 2010, p.18).

A luta pela permanência do nosocômio terminou quando a Cúria Metropolitana, responsável pela administração da Santa Casa de Misericórdia, cedeu em comodato as dependências da instituição. Deveu-se à capacidade da equipe do Imip a restauração do prédio no curto espaço de três anos, contando, para tanto, com os benefícios da Lei Rouanet, após o Conselho Estadual de Cultura ter tombado o imóvel, a partir de um parecer emitido pelo autor destas notas (Pereira, 2007). O aludido instrumento legal permitiu que a instituição obtivesse o auxílio de várias empresas privadas de Pernambuco, além de contar com recursos federais, estaduais e municipais, em verdadeiro mutirão para resgatar o prédio. Esse está terminado e foi inaugurado no dia 16 de agosto de 2010. Dos cinco blocos de enfermarias, projetados inicialmente por Mamede Ferreira para cada um dos lados do edifício, lá estão três à direita e três à esquerda. E na cerimônia de entrega do prédio à sociedade pernambucana, outro príncipe esteve presente: dom João de Orleans e Bragança, um tataraneto do patrono do hospital, assistiu à completude do resgate. 


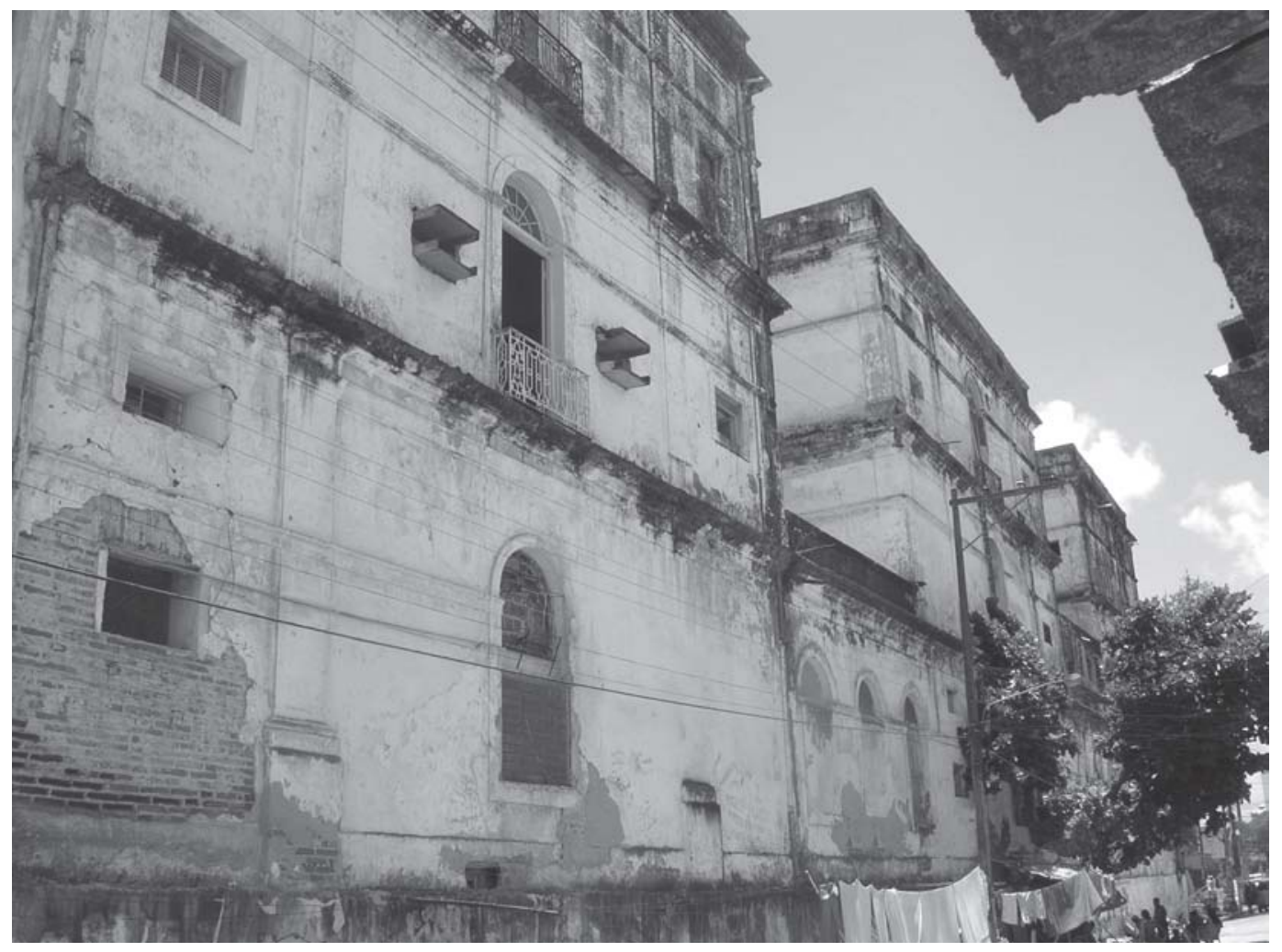

Figura 1: Hospital Pedro II: fachada lateral antes da restauração. 2008. Foto, Marcus Prado

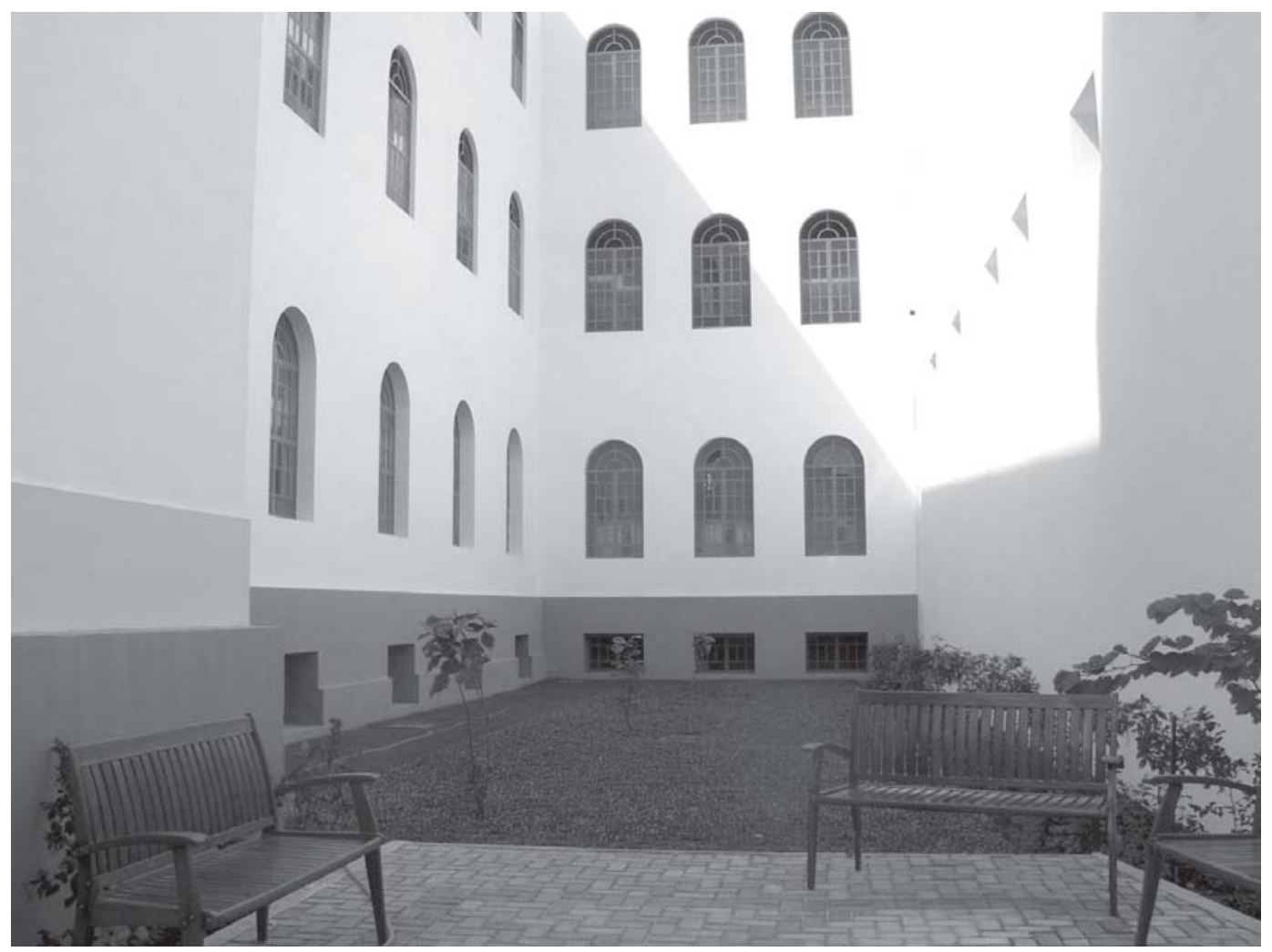

Figura 2: Hospital Pedro II: espaço interpavilhonar já restaurado. 2008. Foto, Marcus Prado 
O velho hospital está em pleno funcionamento, contando com um serviço de reabilitação física, outro de medicina nuclear, no qual está disponível um equipamento Pet-CT, além de radioterapia, hemodiálise e da enfermaria de clínica com sessenta leitos para oncologia de adultos. Também dispõe de dez leitos de UTI de clínica médica e de uma unidade de cuidados paliativos com 12 leitos. Está programada, além disso, a instalação de um Hospital Geral de Transplantes, no qual se possa realizar procedimentos de substituição de córnea, rins, fígado, coração, pâncreas, pulmões e transplantes de medula. Serão 350 transplantes por ano, para os quais funcionarão o bloco cirúrgico, a UTI pós-transplante, ambulatórios pré e pós-transplante, hospital dia e enfermarias (Um hospital..., 2010).

O Imip tem uma tradição peculiar no Recife, devido ao fato de sempre ter acolhido alunos das duas faculdades de medicina, tornando-se, inicialmente, uma escola de pediatria e, em seguida, um lugar para a transferência do conhecimento em geral, nas diversas áreas das ciências médicas. Por isso, fundou a Faculdade Pernambucana de Saúde, em cujas dependências localiza-se a terceira escola médica da cidade. No Hospital Pedro II funcionará, além disso, a Escola Politécnica de Saúde, destinada à formação de profissionais de nível médio, os Laboratórios de Habilidades Clínicas e a Casa do Residente, além do Memorial da Saúde Materno-Infantil Prof. Fernando Figueira (Um hospital..., 2010).

\section{NOTA}

* Trabalho desenvolvido a partir de parecer apresentado pelo autor ao Conselho Estadual de Cultura de Pernambuco.

\section{REFERÊNCIAS}

CABRAL, Renata Campello.

Mário Russo: um arquiteto racionalista italiano em Recife. Recife: Editora da UFPE. 2006.

CZAIJKOWSKI, Jorge Daniel.

Evolucion de los edifícios hospitalarios: aproximacion a una vision tipologica. Disponível em:

http://jdczajko.tripod.com/publicaciones/ aadaih93/evolucion_tipos_hospitalarios.htm Acesso em: 31 mar. 2009. 1993.

FREITAS, Octavio.

História da Faculdade de Medicina do Recife, 1895-1943. Recife: Imprensa Oficial. 1944.

GESTEIRA, Heloisa Meireles.

O Recife holandês: história natural e

colonização nerlandesa. Revista da Sociedade

Brasileira de História da Ciência, Rio de Janeiro, v.2, n.1, p.6-21. 2004.

IVAMOTO, Henrique Sewiji.

A Santa Casa da Misericórdia de Santos: sinopse histórica. Acta Medica Misericordioe, São Paulo, v.1, n.1, p.7-10. 1998.

INVENTÁRIO...

Inventário arquitetônico e diretrizes para a restauração do Hospital Pedro II. Texto e produção de Renata Calumby e Rafaela Lima. Locução de Karoline Fernandes. Recife: T2 Imagem. DVD (9 min). 2007.

KHOURY, Yara Aun (Coord.).

Guia dos arquivos das santas casas de misericórdia do Brasil (fundadas entre 1500 e 1900).

São Paulo: Cedic; Imprensa Oficial do Estado. v.1. 2002.

LEITE, Serafim.

História da Companhia de Jesus no Brasil. Lisboa: Livraria Portugália; Rio de Janeiro: Civilização Brasileira; Instituto Nacional do Livro. 10 v. 1938-1950.

NOGUEIRA, Meuse.

Crise do Pedro II: apenas interesses contrariados. Diário de Pernambuco, 6 jun. 1982. Disponível em: http://arquivo.pernambuco. com/isearch/interface/interface.jsp?Caderno= A\&Midia $=1 \&$ Pagina $=12 \&$ Data $=06 / 06 /$ 1982\&ParametroImagemPequena=/images/ smallimage/DP/DP1982\%20JUN\%20D1/1982/ 06/06/DP1982-06-06-. Acesso em: 14 abr. 2009. 1982. 
PARAÍSO, Rostand.

A Velha Senhora. Recife: Edições Bagaço. 2004.

PARAÍSO, Rostand.

Apelo ao bom senso. Jornal do Commercio, Recife, p.18. 25 fev. 2010.

PEREIRA DA COSTA, Francisco.

Anais pernambucanos. Pernambuco: Arquivo Público Estadual. v.1. 1951.

PEREIRA, Geraldo.

A imprensa médica em Pernambuco:

publicações da sociedade. In: Associação Médica de Pernambuco: 170 anos. Edição

Comemorativa. Recife: Editora Universitária (no prelo).

PEREIRA, Geraldo.

O Hospital Pedro II: afinal uma desejada restauração. Anais da Faculdade de Medicina da Universidade Federal de Pernambuco, Recife, v.52, n.1, p.1-2. 2007.

REGULAMENTO...

Regulamento para o Serviço Sanitário do Hospital Pedro II e dos estabelecimentos a cargo da Santa Casa de Misericórdia do Recife. Recife: Typografia Mercantil. 1898.
RELATÓRIOS...

Relatórios da Santa Casa de Misericórdia do Recife. Recife: Typographia Mercantil. 1880.

ROCHA, Leduar de Assis.

História da medicina em Pernambuco, séculos XVI, XVII e XVIII. Recife: Arquivo Público Estadual. 1960.

SILVA, Kleber Pinto.

A ideia de função para a arquitetura: o hospital e o século XVIII: parte 6/6. Função, um conceito?: aprendendo com Tenon e considerações finais. Arquitextos, n.19. Texto especial n.111. São Paulo: Portal Vitruvius. Disponível em: http://www.vitruvius.com.br/ revistas/read/arquitextos/02.019/823. Acesso em: 3 maio 2008. 2001.

UM HOSPITAL...

Um hospital para toda vida. Movimento Médico. Recife, ano 7, n.17, p.8-9. 2010.

WATJEN, Hermann Julius Eduard.

O domínio colonial hollandez no Brasil. São Paulo: Companhia Editora Nacional. Disponível em: http://www.liber.ufpe.br/visaoholandesa/ Get.vh?page.id=653\&query=construção\% \}20de\%20um\%20hospital\%20no\% 20recife\&page.number=393 Acesso em: $17 \mathrm{fev}$. 2009. 1838.

\section{$\rightarrow \rightarrow \rightarrow<<<$}

